\title{
Internet of Things: Smart Home Automation System using Raspberry Pi
}

\author{
Smita Mahindrakar ${ }^{1}$, Ravi K. Biradar ${ }^{2}$ \\ ${ }^{1}$ Pillai college of Engineering, Mumbai University, Mumbai, India \\ ${ }^{2}$ Assistant Professor, Department of Electronics, Pillai College of Engineering, Mumbai, India
}

\begin{abstract}
In this busy and comfortable lifestyle of peoples, communication technology has evolved in such a way that any information will be accessed from anywhere, at any time, by any one. In today's communication technology, communication is not only constrained between two computers, but it is a complete network called internet. With advance internet technology today not only we can access the information from anyplace, at any time, by any person, but we can also control and monitor various devices from anyplace, at any time, by any authenticated person, this technology is called Internet of Things (IoT). This report represents the application of IoT for Smart Home Automation system which includes a Raspberry Pi as a processing unit for data which is extracted from various sub-systems like, Temperature sensing system, Automatic light system, Cooling system, Gas detection system, Water level sensing system, Motion detection system and Lights on and off system. All these systems are monitored and controlled remotely by a webpage.
\end{abstract}

Keywords: Internet of Things (IoT), Raspberry Pi, Smart Home Automation System (SHAS)

\section{Introduction}

Today worldwide multitude of Internet connections are devices used directly by humans like computers and mobile handsets, in other words we can say it's a human to human communication. In not a distance future, it's possible that we can have not only human-human communication but also device-device communication which is called "Internet of Things" where Things refers to various electronic devices.

The term 'Internet of Things' was firstly coined by Kevin Ashton in a presentation in 1998, he described a IoT as a system where the digital world is connected to the physical world forming a global network [1].

With IoT not only we can access the information from anyplace, at any time, by any person, but we can also control and monitor various devices from anyplace, at any time, on any network, by any authenticated person, this technology is called Internet of Things (IoT).

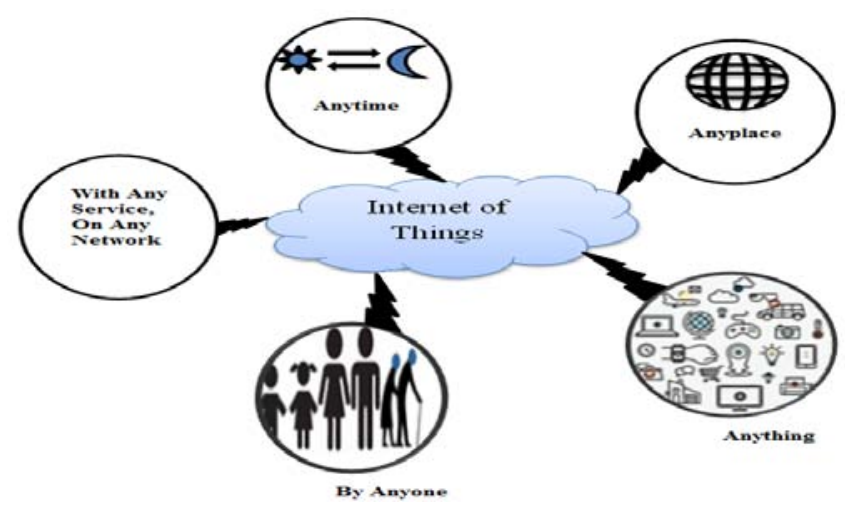

Figure 1: Internet of Things

The concept of IoT aims in making Internet more ubiquitous and immersive. Thus accelerating the internet to make it enable by any authorized person for easy access and to have an interaction with enormous variety of devices for instance, home gadgets, spying cameras, monitoring sensors, actuators, automobiles, displays, and so on, the IoT will nurture the development of a number of applications that make use of the virtually enormous amount and variety of data generated by Things to provide new benefits to citizens, industry, and government sectors.

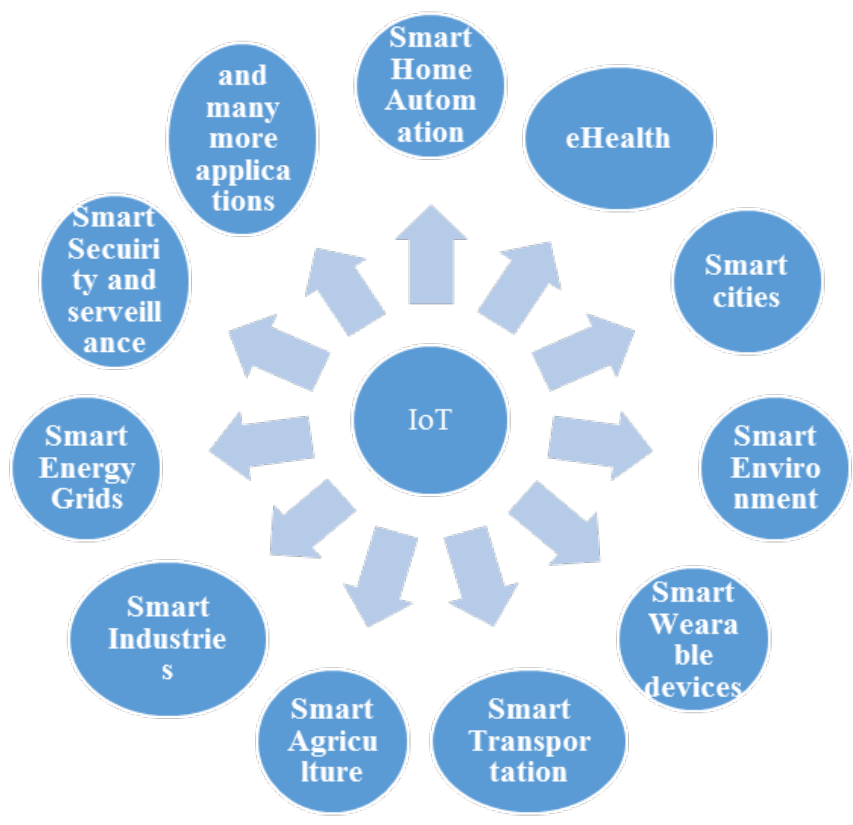

Figure 2: Applications of IoT

The enrichment of IoT technology is revolutionizing enormous sectors such as energy efficiency, healthcare, automation of home and industry, financial services, nanotechnologies and so on [2]. IoT technology is perforating new doors to provide intelligent, comfortable and improved quality of life. In other words we can say that IoT is making methodological way of living into a smart IoT life where not only industry or home but entire city can be 


\section{International Journal of Science and Research (IJSR) \\ ISSN (Online): 2319-7064}

Index Copernicus Value (2015): 78.96 | Impact Factor (2015): 6.391

shaped into smart city. There are vast range of IoT applications like eHealth, Smart home, Smart cities, Smart environment, Smart agriculture, and etc.

\section{Literature Survey}

Now a days many more digital appliances are populated in our homes, it is necessary that all of them have to be networked in such fashion that they can be monitored and controlled from anywhere, at any time, by an authenticated person, this is called Smart Home Automation System (SHAS). SHAS provides comfort, security, and energy efficiency of an in-home environment equipments.

Home automation technology can make home environment more convenient. If user is at work or on vacation, a HAS is built in such a way that it should notify the user about the present condition of an in-home environment and also should take required precaution measures in emergency.

The development of SHAS has existed for many years, the term "smart house" was coined by American Association of House builders in 1984 [4]. It all started with group of students who did a simple experiment on alarm clock whose two hands where connected to the two electric wires which in turn created a closed circuit of battery and a bulb at particular time of the clock when two hands of clock meet. Thus making the bulb glow to glow when user wishes. Today we see a significant increase in home automation technology due to higher affordability and advancement in Smart phones which allows vast connectivity.

[5] Dhawan S. Thakur and Aditi Sharma,

This paper proposes a Voice control and Zigbee based Home Automation System, in this system user has to give a voice command to control the in-home appliances. Here Zigbee is used to communicate between base station and remote station. Both base station and remote station are placed in such a range that the Zigbee communication is possible. This system cannot be used outside the range of Zigbee communication.

[6] Akanksha Singh, Arijit Pal, Bijay Rai,

This paper proposes a GSM based Home Automation System where user can control the in-home appliances by sending the SMS to an HAS placed in home environment.

In this system user sends the message to the GSM modem which is interfaced with the microcontroller. Microcontroller in-turn turns on the required devices through the switching module.

A GSM and ZigBee based communication and control for home appliances has been presented by many of researchers the drawback of these systems is that in ZigBee, range plays important role and in GSM, at remote places there should be proper coverage of GSM mobile signal. The above mentioned systems have made momentous endowment to the design and development of home automation systems.

[2] Rajeev Piyare,

This paper proposes an Arduino based Home Automation System, in this system various sensors are used to sense the data and this data is updated on a webpage through the Arduino processor and even user can control the device through internet.

Drawback of this system are Arduino does not have Ethernet shield and compatibility of operating system for programming.

To overcome all these drawback we have used an Raspberry $\mathrm{Pi}$ as a core processing unit so as to satisfy the need of IoT.

\section{System Architecture and Functions}

\subsection{System Architecture}

If we generalize the architecture of IoT, system should have 3 major layers, and they are,

1) Perception layer (Things): real-time devices such as sensors, camera, RFID etc., which has unique identity in a virtual world. Data of these devices can be accessed and monitored and controlled.

2) Middleware layer: this layer acts as connectivity between the physical world with the virtual world. In this the accessed data is forwarded from perception layer to next layer.

3) Application layer: depending on required application like smart HAS, smart industry etc., this layer is the user end layer where user can use data from middleware layer to perform required action like monitoring or controlling the information system.

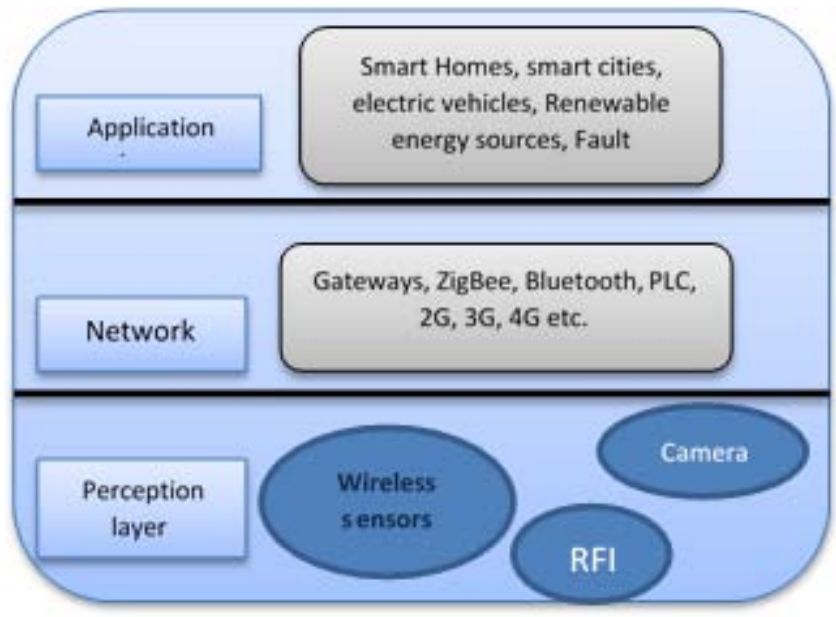

Figure 3: Architecture of IoT[11]

\subsection{System Architecture}

The proposed system consists of various sensors which are placed in-home environment to sense various parameters and this data is processed and is updated on a dedicated web page which allows users to control and monitor various inhome environments things.

Functions of various sensor used in proposed system are, 1)PIR sensor which sense the motion and turns on the light

2)LDR sensor which checks the intensity of light in the room and automatically turns on the room light

3)Temperature sensor which checks the temperature of the room and turns on the fan in that room

\section{Volume 6 Issue 1, January 2017




\section{International Journal of Science and Research (IJSR) \\ ISSN (Online): 2319-7064}

Index Copernicus Value (2015): 78.96 | Impact Factor (2015): 6.391

4)Smoke or gas detector sensor which detects the smoke and turns on the buzzer alarm and all these are update on the web page

5)Camera module which gives the live streaming of the inhome environment on a web page

6)Heater which can be turned on through remote area through web page.

7)Water level sensor which checks the water level in the tank so as to turn on the heater.

Raspberry pi is the core processing unit in this system where all sensors are interfaced and as it acts as a local server it helps to send data to cloud and receive data from cloud which helps user to remotely control and monitor the system.

\section{System Design and Implementation}

The main aim of this system is to satisfy the requirement of Smart Home Automation System, that is an IoT based Home Automation system. Once we have integrated with the architecture and various functions of each sensor in our system it's time to design the hardware and implement our idea.

\subsection{System Design}

Fig shows the hardware design of the proposed system.

\subsubsection{Sensors and Camera}

PIR sensor which sense the motion and turns on the light. LDR sensor which checks the intensity of light in the room and automatically turns on the room light. Temperature sensor which checks the temperature of the room and turns on the fan in that room. Smoke or gas detector sensor which detects the smoke and turns on the buzzer alarm which acts as a fire detection system also and all these are update on the web page. Heater which can be turned on through remote area through web page. Water level sensor which checks the water level in the tank so as to turn on the heater. Camera module which gives the live streaming of the in-home environment on a web page

\subsubsection{Raspberry Pi}

The Raspberry pi is a low cost, credit-card sized called as a system on a chip that plugs into a computer monitor or

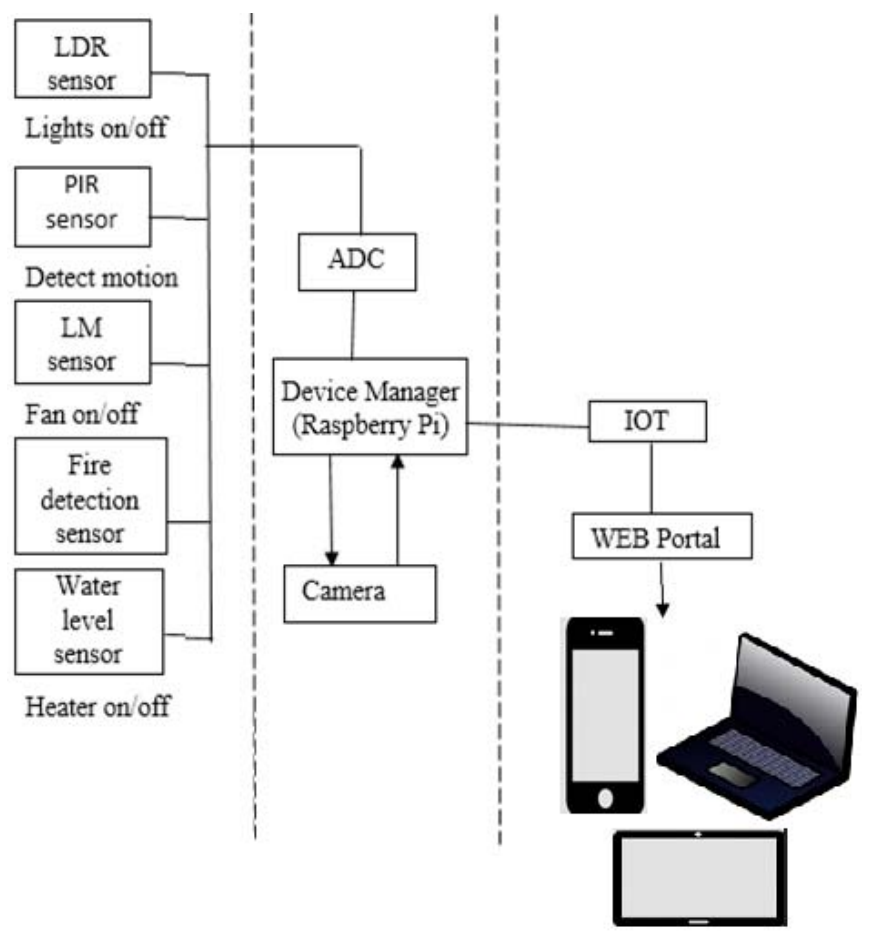

Figure 4: Hardware Design

$\mathrm{TV}$, and uses a standard keyboard and mouse for operation. Operating system which is predominantly used in Raspberry $\mathrm{Pi}$ is Linux kernel. Rasbian operating system which is based on Debian Linux is used to control Raspberry Pi which is optimized for Raspberry Pi hardware. Here we are using Raspberry Pi 2. Primary setup of raspberry pi is extract the Rasbian OS on to SD card and at this stage configure Raspberry Pi using Raspi-config command, than to enter desktop use command startx command. Wiring Pi is a library which is very important so as to acess the GPIO pins of Raspberry Pi.

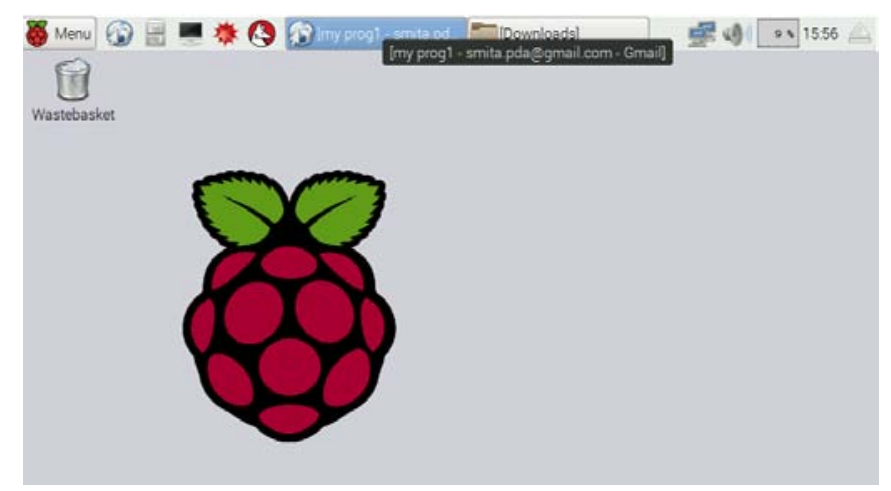

Figure 5: Raspbian OS Desktop

\subsubsection{Qt Creator}

Qt is a cross-platform application framework that is widely used for developing application software that can be run on various software and hardware platforms with little or no change in the underlying codebase, while having the power and speed of native applications. It runs on major the major desktop platforms and some of the mobile platforms. 


\section{International Journal of Science and Research (IJSR) \\ ISSN (Online): 2319-7064}

Index Copernicus Value (2015): 78.96 | Impact Factor (2015): 6.391

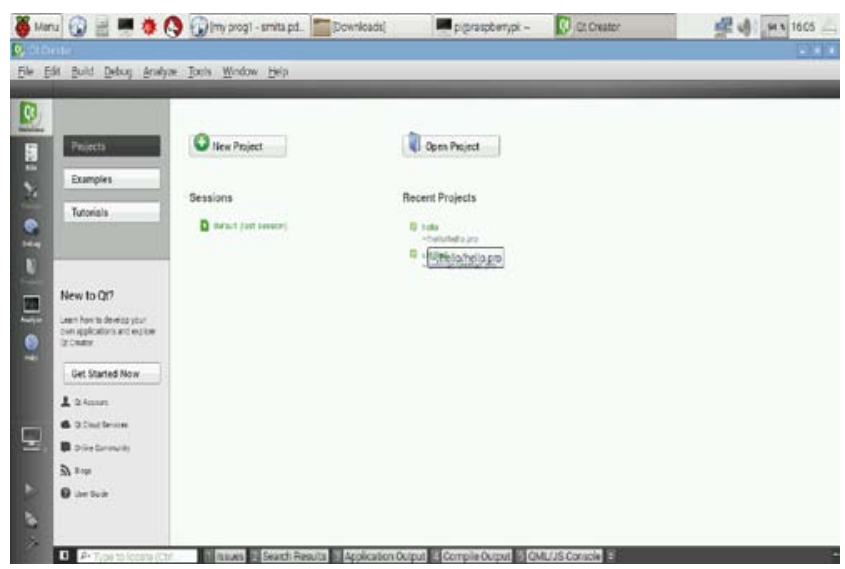

Figure 6: Qt Creator Platform

\subsection{Implementation Steps}

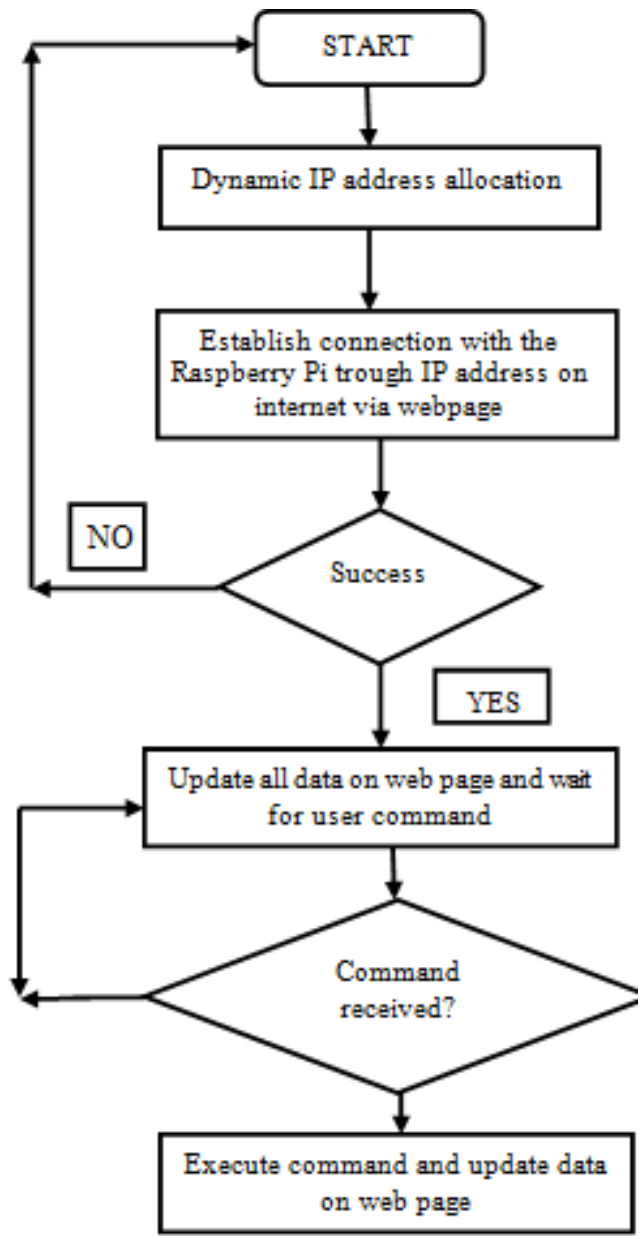

Figure 7: Flow Chart Description of Proposed system

\section{Results}

A webpage that can be operated on any internet accessible device such as mobile, laptop, desktop, tablet etc. fig Shows the webpage layout as we can see values of many sensors and a button to turn on and off the heater and fig shows the online streaming of the in-home environment.

\begin{tabular}{|c|c|}
\hline${ }^{x} \square$ & $\theta 0$ \\
\hline$\leftrightarrow \rightarrow$ C 192.168.1.102:8085 & $\Leftrightarrow \equiv$ \\
\hline Z: Apps OHPConsted & \\
\hline
\end{tabular}

\section{RENOTE HONE AUTO MATION}

\author{
Temperture:3Sdeg \\ LDR-199 \\ SMOKE 512 \\ MOTIOX:YES \\ WATER LEVEL-LOW
}

HEATERON

HEATEROFF

Figure 8: Webpage of Smart Home Automation System

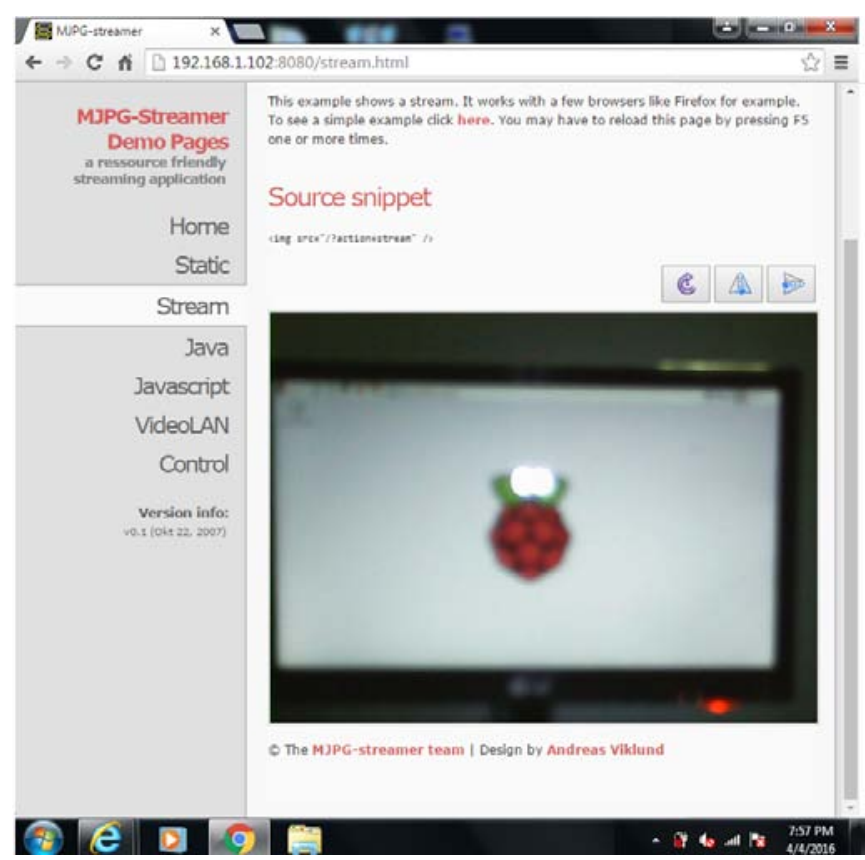

Figure 9: Live Web Streaming from a Camera

\section{Conclusion}

Smart home automation system which is the most commercial application of Internet of Things has experimentally verified satisfactorily we have connected the small appliance to it and we were able to control them remotely through the internet using the webpage and also can monitor the area surrounding through the camera installed in that area. This will help the users of any age to control and monitor their home from anywhere in the world at any time.

\section{References}

[1] K. Ashton, “That 'Internet of Things' Thing”, RFID Journal, 22 June2009.

[2] Rajeev Piyare, "Internet of Things: Ubiquitous Home Control and Monitoring System using Android based Smart Phone”, International Journal of Internet of Things 2013, 2(1): 5-11

[3] Dr.Ovidiu vermesan and Dr.Peter fries, "Internet of things-from research and innovation to market development”, River publication, 2014. 


\section{International Journal of Science and Research (IJSR) \\ ISSN (Online): 2319-7064 \\ Index Copernicus Value (2015): 78.96 | Impact Factor (2015): 6.391}

[4] Suraj Bhatia,Jatin Bajaj, M. Mani Roja "Technology, Systems and Implementation of a Smart Home Automation System: A Review” IJCTA Sept-Oct 2014, ISSN:2229-6093.

[5] Dhawan S. Thakur and Aditi Sharma, "Voice Recognition Wireless Home Automation System Based On Zigbee”, in IOSR Journal of Electronics and Communication Engineering (IOSR-JECE), Volume 6, Issue 1, May. - Jun. 2013

[6] Akanksha Singh, Arijit Pal, Bijay Rai, "GSM Based Home Automation, Safety and Security System Using Android Mobile Phone” in International Journal of Engineering Research \& Technology (IJERT), Vol. 4 Issue 05, May-2015.

[7] A. Bonnaccorsi, "On the Relationship between Firm Size and Export Intensity,” Journal of International Business Studies, XXIII (4), pp. 605-635, 1992. (journal style)

[8] Dr.Ovidiu vermesan and Dr.Peter fries, "Internet of things-from research and innovation to market development”, River publication, 2014.

[9] Dongyu wang,Dixon lo,janak bhimani and kazunori sugiura, “ Anycontrol-IOT based appliances monitoring and controlling ”, IEEE 39th Annual International Computers, Software \& Applications Conference, 2015.

[10] Dongxin Lu and Tao Liu, "The Application of IOT in Medical system” in IEEE,2011.

[11] Manar Jaradata, Moath Jarraha,c, Abdelkader Bousselhamb, Yaser Jararweha,*, Mahmoud AlAyyouba, "The Internet of Energy: Smart Sensor Networks and Big Data Management for Smart Grid”, in The International Workshop on Networking Algorithms and Technologies for IoT (NAT-IoT 2015),ELSEVIER publication.

[12] Lu Tan and Neng Wang, “ Future Internet: The Internet of Things”, in 3rd International Conference on Advance Computer Theory and Engineering ,2010 IEEE V5.

[13] Mircea Murar , Stelian Brad "Monitoring and controlling of smart equipment using Android compatible devices towards IoT applications and services in manufacturing industry", in IEEE,2014.

[14] Chakib BEKARA, "Security Issues and Challenges for the IoT-based Smart Grid by" in International Workshop on Communicating Objects and Machine to Machine for Mission-Critical Applications (COMMCA-2104), ScienceDirect, ELSEVIER, 2014.

[15] Andrea Zanella and Lorenzo Vangelista," Internet of Things for Smart Cities by" in IEEE INTERNET OF THINGS JOURNAL, VOL. 1, NO. 1, FEBRUARY 2014

[16] Y. Liu, "Study on Smart Home System Based on Internet of Things Technology," in Informatics and Management Science IV. vol. 207, W. Du, Ed., ed: Springer London, 2013, pp. 73-81.

[17] M. A. Al-Qutayri and J. S. Jeedella, "Integrated Wireless Technologies for Smart Homes Applications," in Smart Home Systems, M. A. AlQutayri, Ed., ed: InTech, 2010

[18] Armando Roy Delgado, Rich Picking and Vic Grout, "Remote-Controlled Home Automation Systems with
Different Network Technologies”, in Centre for Applied Internet Research (CAIR), University of Wales, NEWI, Wrexham, UK,2010.

[19] Somayya Madakam, R. Ramaswamy, Siddharth Tripathi, "Internet of Things (IoT): A Literature Review”, in Journal of Computer and Communications, 2015, 3, 164-173.

[20] Dhawan S. Thakur and Aditi Sharma, "Voice Recognition Wireless Home Automation System Based On Zigbee”, in IOSR Journal of Electronics and Communication Engineering (IOSR-JECE), Volume 6, Issue 1, May. - Jun. 2013

[21] Akanksha Singh, Arijit Pal, Bijay Rai, “GSM Based Home Automation, Safety and

[22] Security System Using Android Mobile Phone” in International Journal of Engineering Research \& Technology (IJERT), Vol. 4 Issue 05, May-2015.

\section{Author Profile}

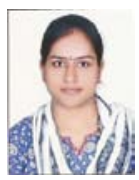

Smita Mahindrakar pursuing ME in Department of Electronics Pillai college of Engineering Mumbai. Completed BE from PDA College of Engineering VTU University.

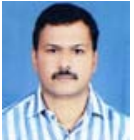

Prof. Ravi K. Biradar working as Asst. Professor at Piilai College of Engineering. He is currently pursuing his $\mathrm{PhD}$ from SGGS, Nanded. His research interests include Control System and Algorithms and Embedded Systems. He has 15 years of teaching

experience. 